\title{
Call the Specification for Scholars to Pursue Academic Researches: Consideration based on a Number of Academic Events in $\mathbf{2 0 0 0}$
}

\author{
Juan ZHOU \\ Nanjing Xiaozhuang University, Nanjing 211171, China
}

\begin{abstract}
Academic research is a scale for measuring the social civilization level. Pursuing academic researches is a lifestyle of the academic circles, and the specification for pursuing academic researches the basic requirement of the academic circles. A number of academic events in 2000 have played an impact on scholars to pursue academic researches. Therefore, the studies of academic research misconduct events are chosen for putting forward related suggestions, aiming to promote academic researches to return to the question and exploration of profound learning in a clean environment.
\end{abstract}

Keywords: Academic Events; Misconducts; Profound Learning; the Specification for Pursuing Academic Researches

\section{Introduction}

For a long time, pursuing academic researches is a lifestyle of the academic circles. The "profound learning" pursued in the academic circles is often out of the sight of people, and therefore, scholars are naturally the guardians of it. However, who are the supervisors of these guardians? In fact, the answer is blank, and scholars themselves are the only guardians and supervisors. Today, higher education (institutions of higher learning) has increasingly become the center of the society, and simultaneously the activities of the scholars are widely being focused by the masses. The specification and moral standard for scholars to pursue academic research are important aspects of people to respect academic research and scholars. The moral standard for scholars is also becoming an important aspect of the social morality.

2. The differences will directly affect the scholars to the self-constraint of academic research morality.

The differences of scholars in academic level, learning attitude, academic tendency, political condition, and economic and social statuses will directly affect the scholars to the self-constraint of academic research morality. For a long time, people think that the mystery of scholars in pursuing profound learning is high, but the studies of the professional functions of professors (scholars) are rare $(\mathrm{P} \bullet \mathrm{G} \bullet$ Altbach). But the above differences always exist between scholars. As individuals with unique values and code of ethics, scholars can only rely on their own supervision in academic research, but problems are easy to cause once their self-interest is affected.

Everyone always admires the famous persons in the academic circles, because they exhaust the whole life to pursue and explore many unknown fields and light the holy flame of different knowledge, making the wisdom of human beings illuminated. However, the sacred, holy academic circles are being endangered to loss balance, because academic corruption is occurring.

In the eyes of ordinary people, academic 
circles are very strict in all aspects. In recent years, however, all kinds of academic "papers" and "works" with inferior-quality, repetitive or even plagiarized contents have been released greatly in the world. Papers can be published by spending money and even can be written by others. YANG Yushen, Academic Criticism Network founder, in the history department of Beijing Normal University, divides the currently unhealthy tendency and corruption in the academic circles into five forms: (1) low-level repetition; (2) rough production; (3) foam academic research; (4) forged and fake papers; (5) plagiarized contents. Some scholars even plagiarize the results of the domestic and foreign counterparts, and release fake papers by faking the experimental data, and win popularity by hoodwinking the public; students plagiarize the results of teachers, and vice versa. YANG Yusheng compares the phenomenon to be a widely spreading "academic locust disaster" that is difficult to restrain.

The spreading of academic corruption and the loss of academic norms give rise to severe challenges to the academic circles. The educational world as the main field of scholars to survive should be a pure land for social morality and also of great significance to correcting the general mood of society and promoting the social civilization. However, the corruption is not limited to the above mentioned problems in both educational and academic cycles. In China's Education Development Report 2000, YANG Dongping pointed out that fake diploma overflows in the society and has become a public nuisance. It is reported that there have been about 500,000 or 600,000 in-service staff with a fake diploma in the educational world. In 2000, the college graduation certificates of 138 out of 345 candidates signing up for being private teacher in Xi'an were faked, accounting for as high as $40 \%$ (China youth daily, 11/15/2000).

More seriously, the combination and exchange of rights with learning or money with learning exist, just as an old Chinese saying goes, "a good official can more widely study for a better future; a good teacher can become an official for promoting kindness ethics better". At present, the graduate programs requiring no entrance examination are springing up everywhere. For example, there were more than ten graduate programs such as human resources management (the department of psychology), regional economics (the department of cities and environment), and business management (school of economics) offered by Peking University from Agues to September in 2000. At the same time, there were more than 20 short-term graduate training classes in Peking University. In addition, graduate programs are also offered by Peking University in Chongqing, Guangzhou, Taiyuan, etc. Just because of this type of graduate programs, the unprecedented prosperity of further education using public funds appears. Some experts had questioned this type of training (learning) and thought it was impossible for this type of students to possess an equivalent education level with the full-time graduate students within a short time and without paying more time and energy (Beijing Evening News, 09/11/2000). What's more, they failed to pass the postgraduate entrance examination. This way has also become a kind of corrupt practice. Not surprisingly, some officials almost don't need to go to school or let the secretary substitute them in school, and even hire somebody to write graduation thesis and acquire a degree. Compared with the flooding fake diploma as a public nuisance, the false composition in the real degree makes people uneasy to identify, and will exert a greater harm than the faked diplomas sold by the street vendors.

The actual problems are more than the above mentioned. At the Chinese people's political consultative conference in March 2000, WANG Shouchang used to angrily dwell on all sorts of academic corruption practices and the most unacceptable was that the construction of doctor, master or postdoctoral education sites or the selection of supervisors has not been yet 
evaluated. However, all sorts of nonacademic public relations activities have been implemented more or less. Many people often buy gifts for setting up a good relationship, hire exports to provide lectures for getting famous, or greet somebody known by some experts. People with power publish books using the public funds so as to acquire praises and academic titles and become a tutor of PHD students. In some places, works and papers are even sold for people needing to get professional titles and degrees.

Besides, the high and new technologies are constantly emerging, and every revolution of science and technology have a significant impact on the society. As Wiener, founder of "cybernetics" wiener said, "The development of technology will bring infinite possibilities to the good and the evil". Scholars (scientists) cannot shirk their responsibilities for the negative effects from their studies and discoveries.

All the above mentioned suggests that the impact from the great commercial tide should not be ignored in the period of social transition. Also, it is easy to cause chaos once the autonomous morality for scholars to pursue academic research is abused by some people with ulterior motives in the academic circles. Under these circumstances, the morality for scholars to pursue academic research should be reviewed from a new perspective, and also new strategies must be proposed.

In the information society, the volume of information and knowledge has increased fiercely, giving rise to a big impact on the academic circles. In the Internet age, the trend of the world "global village" makes the time and space distance between people greatly shortened. The increase of the information sources lets people much easier to access to information more and more widely. At the same time, the communication and competition between scholars are more frequent in the academic circles. In academic exchanges, the conflict between the academic research moral standard and values of scholars will occur. In the complicated social environment, scholars are taking to the social public view, and the requirements and limitations from the society and government will increase for them as well. Thus, scholars are required to pursue the "inner freedom" like Einstein said, namely, "no constraint from the authority and social prejudice; a spirit with freedom and independent thinking". On the issue of the scholars' responsibility for learning, $\mathrm{J} \cdot \mathrm{S} \bullet$ Brubeck in the United States used to put forward four principles in his book Higher Education Philosophy:

(1) All members of the academic community have to be systematically trained in some field of higher education

(2) Professors keep the autonomy as much as possible

(3) Scholars should be morally responsible for their own discipline and devote themselves to their own field

(4) Bear the responsibility for releasing discoveries to the public

Therefore, scholars need to be responsible for their own research field and prudently adhere to the specification of academic research. Also, they need to resolutely resist the temptation to foreign interests and the academic vanities and enhance the self-cultivation with a strict integrity to consciously go against all sorts of bad phenomena in academic circles. Meanwhile, a series of more objective and impartial academic research moral standard and norms should be explored, and an improvement to the mechanically quantitative management mechanism for the academic activities of scholars needs to be timely focused.

Strengthening the supervision and guidance of public opinion to the academic cycles has been an indispensable aspect. Nowadays, the development of information technology has made the information communication very easy. Newspapers, magazines, television, radio, and the Internet play a very important role in the people's life. Using variety of media functions, scholars can be guided. With the exposure to the 
confirmed academic corruption, scholars can learn lessons from the past and keep an eye on the future. For a long time, the academic circles of scholars are not focused by the masses, but some risk danger in desperation because of a momentary fluke and the possible interest, even if they know it is wrong to cheat. The exposure by public opinion and media, however, makes them nowhere to hide. Furthermore, it is necessary to strengthen the supervision on those scholars who abuse their academic power for research projects, funds or other reasons.

For serious academic corruption, judicial intervention can be called. Driven by interests, some scholars have been prisoned by "ranking of officials" or "money is king" in the academic activities. The judicial intervention will bring them a deterrent power to them.

\section{Conclusions}

It is true that an exploration in the academic research ocean is very austere. Especially now, scholars' academic activities and dignity will be hit in the increasingly complex world. However, adhering to academic research moral standard, rigorous style, seriousness, and moral bottom line should be pursued by the scholars who seek and explore "profound learning".

\section{Acknowledgement}

This paper aided financially by the "Twelfth Five-year" Planning Project of Nanjing, "Study on the Current Situation and Development of the Social Service Ability of the Local Colleges and Universities in Nanjing (No. LQ/2011/002)"; the Key Research Project of Nanjing Xiaozhuang University, "Exploration on the Innovation of the Work of Party Building for College and University Students under the Background of Enrolling Students by the Large Classification of Subjects (No.2014kjkt02)".

\section{References}

[1] J• S• Brubaker. Translated by Chengxu WANG. Higher Education Philosophy [M]. Zhejiang Education Publishing House.

[2] Dongping YANG. China's Education Development Report in 2000. WWW.EDU.CN

[3] Special Topic about Academic Corruption. WWW.EDU.CN 